\title{
Russell's Paradox in Appendix B of the Principles of Mathematics: Was Frege's response adequate?
}

\author{
KeVin C. Klement \\ Department of Philosophy, University of Massachusetts, Amherst, MA 01003, USA
}

Received March 2000

In their correspondence in 1902 and 1903, after discussing the Russell paradox, Russell and Frege discussed the paradox of propositions considered informally in Appendix B of Russell's Principles of Mathematics. It seems that the proposition, $p$, stating the logical product of the class $w$, namely, the class of all propositions stating the logical product of a class they are not in, is in $w$ if and only if it is not. Frege believed that this paradox was avoided within his philosophy due to his distinction between sense (Sinn) and reference (Bedeutung). However, I show that while the paradox as Russell formulates it is ill-formed with Frege's extant logical system, if Frege's system is expanded to contain the commitments of his philosophy of language, an analogue of this paradox is formulable. This and other concerns in Fregean intensional logic are discussed, and it is discovered that Frege's logical system, even without its naive class theory embodied in its infamous Basic Law V, leads to inconsistencies when the theory of sense and reference is axiomatized therein.

\section{Introduction}

Russell's letter to Frege from June of 1902 in which he related his discovery of the Russell paradox was a monumental event in the history of logic. However, in the ensuing correspondence between Russell and Frege, the Russell paradox was not the only antinomy discussed. In September of 1902, Russell wrote to Frege concerning another contradiction, which he also discusses informally in Appendix B of The Principles of Mathematics (Russell 1903: $\$ 500$, Frege 1980: 147-70). Frege, though devastated by the Russell paradox, was not similarly impressed by the latter antinomy, thinking it to be solved by his distinction between sense (Sinn) and reference (Bedeutung). Ironically, however, in this article I show that while it is true that the Appendix B paradox does not arise within Frege's extant logical system, if that system is expanded to include the commitments of Frege's theory of sense and reference, an analogue of this paradox does appear. Frege missed it only because he focused too much on the details of Russell's formulation of the contradiction in logical syntax, and not enough on the Cantorian construction lying behind it. The Principles of Mathematics Appendix B paradox raises serious concerns and problems for Frege's logic and philosophy of language, of which I will be able to offer only a brief diagnosis.

\section{The Appendix B Paradox in Russell's logic}

The Principles of Mathematics Appendix B Paradox, also known as the 'Russell-Myhill Antinomy' is the contradiction that seems to result from considering the class $w$, consisting of all propositions that state the logical product of a class $m$ in which they are not included, along with the proposition $r$ stating the logical product of $w$, and asking the question of whether $r$ is in the class $w$. It seems that $r$ is in $w$ just in case it is not.

This antinomy was discovered by Russell in 1902, a year after discovering the simpler Russell paradox. In his early work (prior to 1907), Russell held an ontology of 
propositions understood as mind independent entities corresponding to possible states of affairs. The proposition corresponding to the English sentence 'Socrates is wise' is thought to contain both Socrates the person and wisdom (understood as a Platonic universal) as constituent entities. These entities are the meaning of declarative sentences. In his early logical systems, propositional variables $p$, $q$, etc., are terms standing for individual entities just as $x$ and $y$. Indeed, the implication sign ' $\supset$ ' was understood not as a statemental connective as it often is now, but as a sign for a primitive relation between the terms flanking it. The formula ' $p \supset q$ ' expresses a relationship between the entities $p$ and $q$, and has the same logical form as ' $a R b$ '. For every well-formed expression a, simple or complex, we can imagine there to exist a proposition as its meaning.

After discovering the Russell paradox in 1901, Russell began searching for a solution. He soon came upon on early version of the theory of types, which is the subject of Appendix B of the Principles. This early theory was a version of what has come to be known as the 'simple theory of types' (as opposed to ramified type theory). The simple theory of types was successful in solving the Russell paradox. However, Russell naturally asked himself whether there were other contradictions similar to the Russell paradox that the simple theory of types could not solve. In 1902, he discovered such a contradiction. Like the Russell paradox itself, Russell discovered this antinomy by considering Cantor's power class theorem: the mathematical result that the number of subclasses of entities in a certain domain is always greater than the number of entities in the domain itself. However, if we are committed to propositions as entities, there seems to be a 1-1 correspondence between the number of classes of propositions and the number of propositions themselves. A different proposition can seemingly be generated for each class of propositions, for instance, the proposition stating that all propositions in the class are true. This would mean that the number of propositions is as great as the number of classes of propositions, in violation of Cantor's theorem. Whenever Cantor's theorem is violated in this way, trouble lurks not far behind. Indeed, in his correspondence with Frege, we find Russell despairing that 'from Cantor's proposition that any class contains more subclasses than objects we can elicit constantly new contradictions' (Frege 1980: 147).

In 1902, Russell's logical notation was borrowed mostly from Peano. In this symbolism, the class $w$ of all propositions stating the logical product of a class they are not in, and $r$, the proposition stating its logical product, are written as follows (Frege 1980: 147):

$$
\begin{aligned}
w & ={ }_{\mathrm{df}} p 3\left[\exists m 3\left\{p .=: q \varepsilon m . \supset_{q} \cdot q: p \sim \varepsilon m\right\}\right] \\
r & ={ }_{\mathrm{df}}\left(q \varepsilon w . \supset_{q} . q\right)
\end{aligned}
$$

In somewhat more contemporary notation, these become:

$$
\begin{aligned}
w & ={ }_{\mathrm{df}}\{p:(\exists m)[p=(\forall q)(q \in m \supset q) . \& . p \notin m]\} \\
r & ={ }_{\mathrm{df}}(\forall q)(q \in w \supset q)
\end{aligned}
$$

Because propositions are entities, propositional variables in Russell's logic can be bound by quantifiers and can flank the identity sign. Russell also allows whole formulae to flank the identity sign, and in such contexts, formulae operate like terms standing for the propositions expressed by the formulae. Thus, $w$ is defined as the class of propositions $p$ such that there is a class $m$ for which $p$ is the proposition that all propositions $q$ in $m$ hold, and $p$ is not in $m$. The proposition $r$ is then defined as the proposition that all propositions in $w$ hold. 
The derivation of the contradiction requires certain principles involving the identity conditions of propositions. These principles were never explicitly formulated in logical notation by Russell, but are informally stated in his discussion of the antinomy in the Principles. However, other writers have sought to make these principles explicit, and even to develop a fully formulated intensional logic of propositions based on Russell's views (Church 1984, Anderson 1986, 1989). With certain assumptions regarding the identity conditions of propositions in place, from either the assumption that $r \in w$ or the assumption $r \notin w$, the opposite follows (see Church 1984: 517-21).

As Russell was all-too aware, unlike the Russell paradox, this paradox cannot be blocked by the simple theory of types (Russell 1903, 500). The simple theory of types only divides entities into individuals, properties of individuals, properties of properties of individuals, and so forth. It makes no further divisions. Propositions, because they are not properties at all, all fall into the type of individuals. The class $w$ is defined as a class of individuals. The proposition $r$ is an individual, and we cannot avoid the question of whether $r$ is in $w$.

Alonzo Church has speculated that this antinomy was the first hint Russell found that what was needed to solve the paradoxes plaguing logicism was something more than the simple (Ramsey-style) theory of types (Church 1984, 516n). If so, then this antinomy is of considerable historical importance, as it might represent the first motivation for the ramified theory of types adopted by Russell and Whitehead in Principia Mathematica. Indeed, later scholars have found letters and manuscripts that show that it was a variant of this antinomy, which Landini (1998: 210-216, 231-232) calls the ' $\mathrm{p}_{\mathrm{o}} / \mathrm{a}_{\mathrm{o}}$ paradox', that forced Russell to abandon his so-called 'substitutional theory' in 1907, and his ontology of propositions along with it.

\section{Frege's response}

Frege's response derives from his distinction between sense and reference. The sense of an expression is a certain 'mode of presentation' or way of picking out its reference. Thus, while ' $3+1$ ' and ' $2 \times 2$ ' have the same reference, it is picked out differently in the two cases; these expressions have different senses. In his reply to the letter sent by Russell articulating the antinomy, Frege responds by asking, 'what is a proposition?' As Frege understands it, a proposition (Satz) is a bit of language, or 'a group of audible or visible signs expressing a thought' (Frege 1980: 149). Frege certainly did not conceive of propositions as having the sort of ontological status Russell ascribed to them. However, as bits of meaningful language, Frege believed that propositions had both senses and references. Frege calls the sense of a complete proposition a 'thought' (Gedanke), and he believed that the reference of a proposition is a truth-value, either the True or the False. Frege understood the True and the False to be objects denoted by propositions just as proper names can denote individuals and ' $2+2$ ' denotes four.

Frege goes on to harshly criticize Peano explicitly (and Russell implicitly) for their sloppiness with regard to this distinction in their logical works. (Russell had used Peano's notation in relating the antinomy to Frege.) What exactly is it that flanks Peano's (and Russell's) connective ' $\supset$ ' in a formula such as ' $p \supset q$ '? Are ' $p$ ' and ' $q$ ' here names for the senses or the references of these propositions? Frege charges that 'on this point Peano is overcome by obscurity and that for this reason he cannot quite explain his sign " $" \supset$ ", (Frege 1980: 150, cf. Frege 1984: 234-48). Does ' $\supset$ ' denote a 
relation between thoughts or a relation between truth-values? Frege contends that Peano seems to give different answers on different occasions. Similarly, when Peano or Russell place the identity sign ' = ' between proposition s or propositional variables, do they mean to express an identity of thoughts or merely an identity of truth-values? In Frege's eyes, Peano's notation is wholly unclear.

In Frege's own logical systems, the sign:

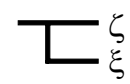

stands for a function that takes as arguments objects, usually truth-values, and yields as value another object, either the True or the False. We might transcribe the assertion, 'If two squared is four, then two to the power of four is sixteen' into Frege's system:

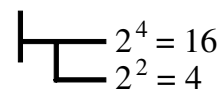

Here ' $2^{2}=4$ ' and ' $2^{4}=16^{\text {' }}$ stand for the references of the propositions ' two squared is four' and 'two to the power of four is sixteen', i.e. they both stand for the True. If these propositions were to flank the identity sign, as in ' $\vdash\left(2^{2}=4\right)=\left(2^{4}=16\right)$ ', this would be seen as the assertion of an identity of truth-values, not of thoughts expressed.

However, thinkers such as Peano are much less clear about their signs, and this, Frege thinks, is precisely what goes wrong with the paradox described above. If one considers Russell's definition of $w$, one quickly sees problems. In the portion, ' $p=(\forall q)(q \in m \supset q)$ ', Russell seems to mean not simply an identity of truth-values, but an identity of thoughts. But in that case, the second half of the identity would involve what Frege calls indirect reference. Here, the expressions refer not to their customary references, but rather to their customary senses. Thus, ' $(\forall q)(q \in m \supset q)$ ' refers not to a truth-value, but to a thought. ${ }^{1}$ However, if this is the case, then in it, ' $m$ ' refers not to a class, but to a sense picking out a class. This would mean that the first occurrence of ' $m$ ' does not refer to the same thing as the second occurrence, which clearly is meant to refer to a class. If these two occurrences of ' $m$ ' refer to different things, it is extremely problematic that they be bound by the same quantifier. Moreover, Russell's derivation of the contradiction requires treating the two occurrences of ' $m$ ' as referring to the same thing.

In Frege's eyes, in deriving the contradiction by taking the two occurrences of ' $m$ ' as coreferential, Russell seems to be committing precisely the same mistake that occurs in the famous derivation:

(1) $S$ believes that the morning star is a planet

(2) the morning star $=$ the evening star

therefore

(3) $S$ believes that the evening star is a planet

For Frege, statements of propositional attitudes or oratio obliqua involve indirect reference. This inference is invalid because the occurrences of 'the morning star' in (1) and (2) do not refer to the same thing. In the first, the expression refers to a sense, in

1 Although even this is problematic, because it is unclear whether, in indirect speech, ' $q$ ' is to be understood as standing for the sense of a truth-value, or the sense of a sense of a truth-value (the sense of a thought). 
the second, to the planet Venus. Russell does the same with his ' $m$ '. Thus, Frege implies that the contradiction cannot even be adequately expressed in a wellconstructed logical system. It only arises in a logical system that conflates or assimilates sense and reference.

\section{The adequacy of Frege's response}

Is Frege's response adequate? It is true that the Russellian formulation given above could not be regarded as adequate within a Fregean logical calculus. It involves using expressions ambiguously as well as illicit quantification into an oblique context. However, what is not so clear is that Frege is not committed to all that is necessary to create the sort of Cantorian construction that lies at the heart of the antinomy. Frege does not have an ontology of propositions, but he does have an ontology of thoughts. Thoughts are understood as mind-independent entities existing in an objective 'third realm' of sense (Frege 1984: 351-372). The thought that Socrates is wise is not exactly similar to the corresponding Russellian proposition; it is instead understood as a complex sense. While Socrates himself is not a component of this thought, the sense of the name 'Socrates' is. Moreover, at this point, Frege had an ontology of classes understood as the extensions or value-ranges of concepts.

If all of the following conditions hold of Frege's understanding of thoughts and classes, then this his philosophy is also in violation of Cantor's theorem:

(C1) There are such things as classes; they have objective existence.

(C2) There are such things as thoughts; they have objective existence.

(C3) There are as many thoughts as there are classes, i.e. for every class, it is possible to generate a different thought.

(C4) Thoughts can be members of classes, and for every class and every thought, the question arises as to whether the thought is in the class.

However, Frege seems committed to all of these conditions. We have already discussed (C1) and (C2). Consider (C3). Is it possible to generate a different thought for every class? It certainly appears so. Some thoughts are about classes. We could, like Russell, consider thoughts expressing the logical product of a certain class. However, the case is made simpler in Fregean logic if we simply consider, for each class, the thought that every object is in that class. Such a thought exists for every class, even if that thought is not true. Moreover, it seems that each such thought will be different. This guarantees that there are as many thoughts as there are classes. Antinomy should result if the question arises for every class and every thought whether the class is in that thought, i.e. if (C4) holds. For Frege, a class is the value-range of a concept. An object is in the class just in case the object falls under the concept in question. However, he is quite adamant that concepts must be defined for all objects (see e.g. Frege 1984: 147-148); for every object and every concept, the question arises as to whether the object falls under the concept. He is also quite clear that thoughts are objects (see e.g. Frege 1979: 194). Thus, Frege seems committed to everything necessary to generate the antinomy.

However, it is true that the antinomy, as far as I can see, cannot be formulated and derived in Frege's extant logical system, the 'Begriffsschrift' of the Grundgesetze. But this is because that system is entirely extensional. It was designed for mathematical purposes: for demonstrating arithmetical truths using purely logical concepts. It was not designed to capture such things as statements of propositional attitudes or other forms of indirect reference. Every complete well-formed expression in it refers to either 
a truth-value or a value-range. The system does not reflect Frege's commitment to the denizens of the third realm of sense. There is no way in it to speak of thoughts or to assert their identity. He claims that he did not introduce notation for dealing with contexts in which one would want to refer to thoughts (as opposed to simply express them) because he 'had no occasion to do so' (Frege 1980: 149).

However, in order to capture such things as propositional attitudes and to be able to talk about the senses of propositions as well as their references, Frege would presumably welcome the expansion of his logical system into the realm of intensional logic. To do this, one would need to create a logical calculus that contains signs for both the senses and the references of expressions, differentiate them as they need to be differentiated, and introduce functions and axioms governing their interrelations. This is not to say that we would create the sort of logic Frege abhors, one in which the same variable of formula is used sometimes for a truth-value, sometimes for a thought, etc., but rather one in which one would have different variables for each and the relationship between the two formalized logically. At one point in his correspondence with Russell, Frege explicitly suggests introducing 'special signs in indirect speech, though their connection with the corresponding signs in direct speech should be easy to recognize' (Frege 1980: 153). However, I will show that once Frege's system is expanded in this direction, it falls prey to the antinomy.

\section{A partial formulation of Fregean intensional logic}

Church and others have already attempted to devise systems of 'the logic of sense and denotation' (Church 1951, 1973-4, 1993, Anderson 1977, 1987, Kaplan 1964). However, the systems developed by Church, while attempting to capture Frege's distinction between sense and reference in a logical calculus, do not attempt to preserve other aspects of Frege's philosophy. I cannot discuss all of the unFregean elements in Church's systems, but let me name just a few. ${ }^{2}$ Because Church knows that Frege's own logical system is subject to the Russell paradox, he abandon's Frege's own system and instead builds his 'logic of sense and denotation' instead upon a system employing a complicated theory of types, and in which names for functions are allowed to stand in subject position. (While Frege himself quantified over both functions and individuals, he did not allow variables representing functions to stand in subject position.) Certainly, it is understandable why Church makes these moves, considering he is interested not in devising an historically accurate Fregean intensional logic, but in devising a feasible intensional logic that is to be seen as at most inspired by Frege. However, this will not help us in answering the question of whether the historical Frege could adequately respond to Russell's antinomy of propositions. ${ }^{3}$

I will instead begin with Frege's actual logical system of the Grundgesetze and suggest ways in which it would be expanded to include some of his commitments regarding senses and thoughts. Since we already know this system is inconsistent, we are not attempting to develop a feasible intensional logic; we are simply attempting to examine the adequacy of Frege's response to Russell. However, I will not employ Frege's own cumbersome notation. I will use ' $\supset$ ' instead of Frege's conditional stroke, ' $\sim$ ' instead of Frege's negation sign, ' $(\forall a)(\ldots a \ldots)$ ' for the quantifier, ' $\{a: \ldots$

2 For more on the unFregean elements of Church's 'Logic of Sense and Denotation', see Klement 2002: ch. 4 .

3 Moreover, John Myhill (1958: 82) has already shown that Church's logic of sense and denotation, in its original formulation, itself falls preys to an antinomy similar to the one under consideration. 
$a \ldots\}$ ' instead of Frege's class notation, and ' $E$ ' for his membership sign. The existential quantifier, disjunction and conjunction signs are defined as usual. However, I retain Frege's semantics. Thus the ' $\supset$ ' in ' $A \supset B$ ' refers to a function in the strict sense, whose value is the False if $A$ is the True and $B$ is something other than the True, and is the True otherwise. The judgment stroke, ' $\vdash$ ' is then used to carry assertoric force.

I use lowercase letters between $a$ and $e$, and between $m$ and $z$, inclusive, as variables ranging over objects. I use lowercase letters between $f$ and $l$ inclusive, as variables ranging over first-level functions. In the expanded system, we also need variables ranging over senses. I use letters between $a^{*}$ and $e^{*}$ and between $m^{*}$ and $z^{*}$, including an asterisk, to range only over complete senses (senses picking out objects). This category includes thoughts, which are senses picking out truth-values. A quantifier of the form $\left(\forall a^{*}\right)\left(\ldots a^{*} \ldots\right)$ thus ranges only over those senses. However, since these senses are themselves objects, it is permissible to instantiate a normal object variable to a variable for a complete sense, though not the reverse. I use uppercase letters between $F$ and $L$ inclusive for variables ranging over incomplete senses picking out first-level functions. It is a matter of controversy in the interpretation of Frege how such incomplete senses are to be understood. Many writers such as Church (1951) and Geach (1976) take these senses to themselves be functions from sense to sense. I find this interpretation problematic for a number of reasons, and take them instead to be a special kind of incomplete entity (see Klement 2002: ch. 3), but for present purposes it is not crucially important which interpretation is taken.

At the core of the expansion of this sort of logical system into a Fregean intensional logic will be the inclusion of a new primitive function sign ' $\Delta$ '. The intended semantics of this sign is as follows:

$\Delta(\xi, \zeta)=$ the True, if $\xi$ is a sense that picks out $\zeta$ as reference, and the False, otherwise.

I borrow the sign ' $\Delta$ ' from Church, although it is worth noting that, like Kaplan (1969: 353), I reverse the position of the arguments. With the introduction of this symbol, it is natural to introduce some logical principles to govern its use. I will only list those principles that immediately suggest themselves and will be important for my later deduction of the contradiction. The first such principle is the following:

Principle $\Delta 1: \quad \vdash(\forall a)(\forall b)(\forall c)[(\Delta(a, b) \& \Delta(a, c)) \supset b=c]$

This principle states that a sense picks out only one reference.

The next principle may be more controversial. It reads :

\section{Principle $\Delta 2: \quad \vdash(\forall a)\left(\exists a^{*}\right) \Delta\left(a^{*}, a\right)$}

This states that there is at least one sense picking out every object. I believe this to be justified in a Fregean intensional logic because, on a standard interpretation, senses are thought to contain descriptive information that pick out their references in virtue of the references uniquely satisfying the descriptive information. If the identity of indiscernibles holds, as Frege believed, then for every object there must be at least one set of descriptive information it uniquely satisfies. While surely, there may be objects that no person does, has or will ever conceive of or denote using language, if we understand senses to be third-realm entities, independent of minds and language, we still must grant the existence of senses picking out these objects.

Principle $\Delta 2$ asserts that every object has a sense that picks it out. If we hold principle $\Delta 2$ to be true, it is natural also to include a principle postulating a sense for 
every function. However, how are we to formulate this principle? Notice that we cannot write it as something along the lines of ' $\vdash(\forall f)(\exists G) \Delta(G, f)$ ', for this would involve putting function letters in subject position, which Frege warns us that we cannot do. Frege tells us little about the nature of senses of function signs. What we do know is that these senses are incomplete entities, that, when saturated by senses picking out objects, yield more complex senses. The sense of the predicate expression '... is human' yields the thought expressed by complete proposition s such as 'Socrates is human', 'Xanthippe is human', etc., when saturated by the senses of names such as 'Socrates' and 'Xanthippe'. Let us suppose in our logical language that ' $f($ )' refers to the concept of being human. Recall that, for Frege, concepts are a type of function, specifically, those that always yield truth-values when saturated by objects as arguments (Frege 1984: 147, 298, Frege 1964: $\$ \S 2-3$ ). In the realm of sense, there may exist one (or more) incomplete entities serving as the senses of $f($ ). Let us suppose that one such entity is $G()$. Even if we understand $G()$ as a function, it is not a concept. It does not yield truth-values. Rather, when $G()$ is saturated by a sense $a^{*}$, it yields a complex sense, in particular, a thought. Thus, if $a^{*}$ is the sense of the constant ' $a$ ', and $G()$ the sense of the function sign ' $f()$ ', $G\left(a^{*}\right)$ is the thought that $f(a)$. While ' $f(a)$ ', refers to a truth-value (the reference of the proposition, 'Socrates is human'), ' $G\left(a^{*}\right)$ ' refers to a thought (the sense of the proposition, 'Socrates is human'.)

Thus, we have the following corollary of principle $\Delta 2$ for functions rather than objects:

Principle $\Delta 3: \quad \vdash(\forall f)(\exists G)\left(\forall a^{*}{ }_{1}\right) \ldots\left(\forall a^{*}{ }_{n}\right)\left(\forall b_{1}\right) \ldots\left(\forall b_{n}\right)\left[\left(\Delta\left(a^{*}{ }_{1}, b_{1}\right) \& \ldots \& \Delta\left(a^{*}{ }_{n}\right.\right.\right.$, $\left.\left.\left.b_{\mathrm{n}}\right)\right) \supset \Delta\left(G\left(a^{*}{ }_{1}, \ldots, a^{*}{ }_{\mathrm{n}}\right), f\left(b_{1}, \ldots, b_{\mathrm{n}}\right)\right)\right]$

This states that for every function of $n$-arguments, there is an incomplete Sinn of $n$ arguments which is such that, what it yields when saturated by $n$ senses, is itself a sense (possibly a thought) whose reference is what would be had if the function were saturated in each corresponding place by the references of each of the $n$ senses. Since this is a difficult principle to state, much less understand, let us examine a very simple instance of this schema for simple one-place functions, e.g. our example $f$ ( ) (being human) :

$$
\vdash(\forall f)(\exists G)\left(\forall a^{*}\right)(\forall a)\left[\Delta\left(a^{*}, a\right) \supset \Delta\left(G\left(a^{*}\right), f(a)\right)\right]
$$

This states that for all functions $f$ there is an incomplete sense $G$, which, when saturated by a sense $a^{*}$, yields a sense picking out as reference the value of function $f$ for the reference of $a^{*}$ as argument. Thus, to return to an example given earlier, if $a$ is Socrates, $a^{*}$ some sense picking out Socrates, then $G\left(a^{*}\right)$ will stand for a thought, and its reference will be $f(a)$, which is the truth-value of Socrates's being human.

On Frege's understanding, thoughts are understood as the complex senses of entire propositions. The senses of whole propositions are composed of the senses of their constituent expressions (see e.g. Frege 1964: §32, 1978: 187-188, 1980: 149, 157). Incomplete senses form wholes with the senses that saturate them. Thus, they always yield different complex senses when saturated by different senses. This seems to justify the following principle regarding these incomplete senses: if $G\left(a^{*}\right)$ and $G\left(b^{*}\right)$ are the same thought, then $a^{*}$ and $b^{*}$ must be the same sense. Put formally, this reads:

Principle $44: \quad \vdash(\forall G)\left(\forall a^{*}\right)\left(\forall b^{*}\right)\left[\left(G\left(a^{*}\right)=G\left(b^{*}\right)\right) \supset\left(a^{*}=b^{*}\right)\right]$

This states that incomplete senses yield the same complex sense only when saturated by the same component senses. 
Here we should note that Frege's logical operators, written here as ' $\supset$ ', ' $\sim$ ', etc., are themselves names of functions included in the range of function quantifiers such as those in principle $\Delta 3$. Thus, we have the following as an instance of principle $\Delta 3$.

$$
\vdash(\exists G)\left(\forall a^{*}\right)\left(\forall b^{*}\right)(\forall a)(\forall b)\left[\left(\Delta\left(a^{*}, a\right) \& \Delta\left(b^{*}, b\right)\right) \supset \Delta\left(G\left(a^{*}, b^{*}\right),(a \supset b)\right)\right]
$$

In order to fulfill Frege's own wish that the 'special signs' used 'in indirect speech' should be such that 'their connection with the corresponding signs in direct speech ... be easy to recognize', let us call the incomplete sense posited by this instance of principle $\Delta 3$, ' $\rightarrow$ ', and instead of writing ' $\rightarrow(\xi, \zeta)$ ', let us instead write ' $(\xi \rightarrow \zeta)$ ' for convenience. (We do not make the supposition that $\rightarrow$ is unique.) Let us then conclude the following:

$$
\text { Principle } \rightarrow 1: \quad \vdash\left(\forall a^{*}\right)\left(\forall b^{*}\right)(\forall a)(\forall b)\left[\left(\Delta\left(a^{*}, a\right) \& \Delta\left(b^{*}, b\right)\right) \supset \Delta\left(\left(a^{*} \rightarrow b^{*}\right),(a \supset b)\right)\right]
$$

How does the incomplete sense ' $\rightarrow$ ' relate to ' $\supset$ '? Of course, they are not the same thing. Whereas, ' $\supset$ ' designates a function that takes two arguments, typically truthvalues, and yields a truth-value, ' $\rightarrow$ ' designates a incomplete entity that becomes saturated by two senses - standardly, themselves thoughts - and yields a thought. Thus, to use our examples of $f(a)$ and $G\left(a^{*}\right), ' f(a) \supset f(a)$ ' is, of course, a tautology, and names the True. It is not the name of a thought, though it expresses one. It is rather the name of a truth-value. However, ' $G\left(a^{*}\right) \rightarrow G\left(a^{*}\right)^{\prime}$ ' is not a tautology, nor does it name the True. Rather, ' $G\left(a^{*}\right) \rightarrow G\left(a^{*}\right)$ ' names a thought that, in turn, picks out the True. We might think of ' $\rightarrow$ ' then as referring to what ' $\supset$ ' expresses. But, whereas ' $\supset$ ', will usually be seen flanked by names of truth-values, and will form a complex expression naming a truth-value, ' $\rightarrow$ ' will normally be seen flanked by names of senses, and will be part of a complex expression naming a thought.

Let us then do something similar for the membership function. Thus, as another instance of principle $\Delta 3$, we get:

$$
\vdash(\exists G)\left(\forall a^{*}\right)\left(\forall b^{*}\right)(\forall a)(\forall b)\left[\left(\Delta\left(a^{*}, a\right) \& \Delta\left(b^{*}, b\right)\right) \supset \Delta\left(G\left(a^{*}, b^{*}\right),(a \in b)\right)\right]
$$

Let us call the incomplete sense so posited ' $\varepsilon$ '. We then have the following:

Principle $\varepsilon$ 1 : $\quad \vdash\left(\forall a^{*}\right)\left(\forall b^{*}\right)(\forall a)(\forall b)\left[\left(\Delta\left(a^{*}, a\right) \& \Delta\left(b^{*}, b\right)\right) \supset \Delta\left(\left(a^{*} \varepsilon b^{*}\right),(a \in b)\right)\right]$

What we have done, in effect, is introduce new signs into our language for senses picking out the conditional and membership functions, although these are not to be presumed to be the unique senses of these functions. We could continue to do the same for negation, identity and for other functions in Frege's logic, but this will be unnecessary for formulating the contradiction.

What will be necessary, however, is to introduce a new primitive sign for the sense of the quantifier. Here I will limit myself only to the quantifier for individuals. Frege understands the quantifier to stand for a second-level function, a function that takes functions as argument. It would stand to reason then that its sense should also be an incomplete sense, but one that is saturated not by an object-sense, but by a first-level incomplete sense. Let us write the sense as such: ' $\left(\Pi a^{*}\right)\left(\ldots a^{*} \ldots\right)$ ' (or with another

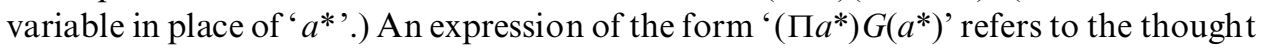
that results when the incomplete sense of the quantifier mutually saturates with the incomplete sense referred to by ' $G()^{\prime}$ '. An expression of the form ' $\left(\Pi a^{*}\right) G\left(a^{*}\right)$ ' always refers to a general thought, and this thought will pick out the True just in case $G()$ is an incomplete sense that when saturated by any sense itself yields a thought that picks out the True. It will refer to a thought picking out the False otherwise.

To take an example, if $G()$ is the first-level incomplete sense of ' $f($ )', where $f()$ is the concept of being human, then whereas ' $(\forall a) f(a)$ ' names a truth-value, ' $\left(\Pi a^{*}\right) G\left(a^{*}\right)$ ' 
names the thought that everything is human. $G()$ is an incomplete sense that yields thoughts when saturated by senses. If ' $(\forall a) f(a)$ ' named the True (that is, if everything were human), then $G($ ) would, for any sense saturating it, yield a thought that picks out the True, no matter what the saturating sense picks out. Therefore, ' $\left(\Pi a^{*}\right) G\left(a^{*}\right)^{\text {' }}$ then denotes a thought that picks out the True if and only if ' $(\forall a) f(a)$ ' denotes the True. Indeed, we may even say, $\left(\Pi a^{*}\right) G\left(a^{*}\right)$ is the thought that $(\forall a) f(a)$. We should then introduce a principle governing the use of this new sign:

\section{Principle $\Pi 1: \quad \vdash(\forall f)(\forall G)\left(\left(\forall a^{*}\right)(\forall a)\left[\Delta\left(a^{*}, a\right) \supset \Delta\left(G\left(a^{*}\right), f(a)\right)\right] \supset \Delta\left(\left(\Pi a^{*}\right) G\left(a^{*}\right)\right.\right.$, $(\forall a) f(a)))$}

This may be difficult to read, and therefore some explanation is in order. In effect, it correlates ' $\left(\Pi a^{*}\right)\left(\ldots a^{*} \ldots\right)$ ' and ' $(\forall a)(\ldots a \ldots)$ ' just as principle $\rightarrow 1$ above correlates ' $\rightarrow$ ' and ' $\supset$ '. It says that for any first-level incomplete sense, $G($ ), picking out function $f()$, the thought $\left(\Pi a^{*}\right) G\left(a^{*}\right)$ has for its reference the truth-value $(\forall a) f(a)$.

This rounds out the Fregean intensional logic here under consideration. I am confident that this is close to the sort of system for the logic of sense and denotation Frege himself would endorse, although it is not a complete development of such a system. Most importantly, however, this system avoids committing the sorts of 'mistakes' Frege sees in logicians such as Russell and Peano. That is, it avoids using the same variables at times for senses of propositions or classes and at times for truthvalues or the classes themselves, etc. Instead, it forces the use of different variables for the sense and reference, but uses ' $\Delta$ ' to express the relationship between them. Indeed, it seems a rather intuitive and plausible approach to the logic of sense and reference for anyone attracted to both a Fregean functional calculus for logic as well as a Fregean philosophy of language. Indeed, one seeming advantage of this rendering is that while we have an 'intensional' logic in the sense that it deals with both intensions and extensions (viz. a logic dealing with senses and thoughts in addition to classes and truth-values, etc.), the logical system here preserves intersubstitutivity of coreferential expressions in all contexts.

\section{Derivation of the contradiction in Fregean intensional logic}

We can now formulate a Fregean version of the Principles Appendix B paradox. Rather than correlating each class with the thought that every thought in the class is true, for the sake of simplicity, we simply correlate each class with the thought that every object is in the class. (However, it is probable that an antinomy can be derived using the former correlation as well.) We then define our problematic class $w$ as follows:

Def. $w \quad w=\left\{p:(\exists m)\left(\exists m^{*}\right)\left[\Delta\left(m^{*}, m\right) \&\left(p=\left(\Pi x^{*}\right)\left(x^{*} \varepsilon m^{*}\right)\right) \&(p \notin m)\right]\right\}$

Here, $w$ is defined as the class of all thoughts $p$ such that there is a class $m$ and a sense $m^{*}$ picking out that class such that $p$ is the thought that every object is in $m$ (as presented through $m^{*}$ ), and $p$ is not in the class $m$. Now, principle $\Delta 2$ guarantees the existence of at least one sense picking out $w$. Let us call one such sense $w^{*}$. In other words, we have:

Principle $w^{*} 1 \vdash \Delta\left(w^{*}, w\right)$

We now define the problematic thought $r$ in terms of $w^{*}$.

Def. $r \quad r=\left(\Pi x^{*}\right)\left(x^{*} \varepsilon w^{*}\right)$ 
We can now ask the question of whether $r \in w$. First, assume that it is :

1. $r \in w$

Because this is an assumption, I do not include the judgment stroke. From (1), the definition of $w$ and class abstraction:

2. $\quad(\exists m)\left(\exists m^{*}\right)\left[\Delta\left(m^{*}, m\right) \&\left(r=\left(\Pi x^{*}\right)\left(x^{*} \varepsilon m^{*}\right)\right) \&(r \notin m)\right]$

Step (2) allows us to consider some $m$ and $m^{*}$ such that:

3. $\Delta\left(m^{*}, m\right) \&\left(r=\left(\Pi x^{*}\right)\left(x^{*} \varepsilon m^{*}\right)\right) \&(r \notin m)$

By the second conjunct of (3), we have:

4. $r=\left(\Pi x^{*}\right)\left(x^{*} \varepsilon m^{*}\right)$

If we replace $r$ in (4) with its definition, we obtain:

5. $\left(\Pi x^{*}\right)\left(x^{*} \varepsilon w^{*}\right)=\left(\Pi x^{*}\right)\left(x^{*} \varepsilon m^{*}\right)$

Consider now principle $\Delta 4$. In it, the variable ' $G$ ' ranges over incomplete senses. However, ' $\left(\Pi a^{*}\right)\left(a^{*} \varepsilon()\right)$ ' names just such an incomplete sense. Frege's logic includes a substitution rule that allows one to instantiate variables to complex formulae of the same type (Frege 1964, §48). Thus we have as an instance of $\Delta 4$ :

6. $\left(\forall a^{*}\right)\left(\forall b^{*}\right)\left[\left(\left(\Pi x^{*}\right)\left(x^{*} \varepsilon a^{*}\right)=\left(\Pi x^{*}\right)\left(x^{*} \varepsilon b^{*}\right)\right) \supset\left(a^{*}=b^{*}\right)\right]$

Instantiating $a^{*}$ and $b^{*}$ to $w^{*}$ and $m^{*}$ in (6) we get:

7. $\left(\left(\Pi x^{*}\right)\left(x^{*} \varepsilon w^{*}\right)=\left(\Pi x^{*}\right)\left(x^{*} \varepsilon m^{*}\right)\right) \supset\left(w^{*}=m^{*}\right)$

By (5) and (7) and modus ponens:

8. $w^{*}=m^{*}$

Then, by substitution of identicals in the first conjunct of (3), we get

9. $\Delta\left(w^{*}, m\right)$

Principle $\Delta 1$ states that senses have unique references. Instantiating it to $w^{*}, m$ and $w$, we get:

10. $\left(\Delta\left(w^{*}, m\right) \& \Delta\left(w^{*}, w\right)\right) \supset(m=w)$

By principle $w^{*} 1,(9),(10)$ and modus ponens:

11. $m=w$

Then, by substitution of identicals on the third conjunct of (3):

12. $r \notin w$

This contradicts our assumption in (1). However, assume instead:

13. $r \notin w$

Then, by (13), the definition of $w$ and class abstraction:

14. $\sim(\exists m)\left(\exists m^{*}\right)\left[\Delta\left(m^{*}, m\right) \&\left(r=\left(\Pi x^{*}\right)\left(x^{*} \varepsilon m^{*}\right)\right) \&(r \notin m)\right]$

By applying rules of the quantifiers and propositional logic to (14):

15. $(\forall m)\left(\forall m^{*}\right)\left(\left[\Delta\left(m^{*}, m\right) \&\left(r=\left(\Pi x^{*}\right)\left(x^{*} \varepsilon m^{*}\right)\right)\right] \supset r \in m\right)$ 
Instantiating (15) to $w$ and $w^{*}$, we arrive at:

16. $\left[\Delta\left(w^{*}, w\right) \&\left(r=\left(\Pi x^{*}\right)\left(x^{*} \varepsilon w^{*}\right)\right)\right] \supset r \in w$

By principle $w^{*} 1$, the definition of $r,(16)$ and modus ponens, we arrive at:

17. $r \in w$

Thus, from either assumption, the opposite follows. Frege has not avoided the antinomy after all. Elsewhere, I give a fully axiomatic demonstration of this antinomy in a more complete logical calculus for the theory of sense and reference (Klement 2002: ch. 6).

\section{Possible solutions}

Frege's philosophy does commit him to all that is necessary to create the diagonal construction involved in the Principles of Mathematics Appendix B paradox. Frege seems to have missed it only because he failed to develop his logical system sufficiently in order for it to capture the metaphysical commitments of his own theory of sense and reference. Developing even a small part of a logical system that reflects these metaphysical commitments reveals flaws in Frege's overall logic and philosophy of language that have been scarcely noticed or discussed. ${ }^{4}$ Frege's commitment to such a large third realm of sense, such that a thought exists for every class, is inconsistent with his commitment to logical entities such as classes and functions. If Frege's philosophy is to be consistent with Cantor's theorem, it must abandon or alter its metaphysics. As it is, Frege's 'third realm' is just too darn big. We noted earlier that the antinomy is derived from an understanding of classes and thoughts that is committed to all of conditions ( $\mathrm{C} 1)$ through (C4). Any possible solution to the antinomy would involve rejecting one of $(\mathrm{C} 1)$ through $(\mathrm{C} 4)$. Let us consider whether Frege, or someone with a broadly similar philosophical orientation, could or should seriously consider abandoning any of these commitments.

Rejecting $(\mathrm{C} 1)$ is perhaps quite attractive. After all, Frege's commitment to naive class theory, enshrined in his infamous Basic Law V, is what leads to the simpler Russell paradox in his system. Without Basic Law V, the extant logical system of Grundgesetze is consistent. One might suspect then, that the Principles Appendix B paradox is just an intensional byproduct of the same flaw in Frege's logic. Abandon classes, and perhaps all will be well.

However, things are not quite so easy. As it turns out, an antinomy very similar to the Principles Appendix B paradox can be formulated in the sort of Fregean intensional logic here under consideration even if that system drops its commitment to naive class theory. The antinomy we have been discussing draws a Cantorian diagonal construction between classes and thoughts. However, we could instead draw a Cantorian diagonal construction between concepts and thoughts. Consider the concept being a thought for which there is a concept such that the thought is the thought that every object falls under the concept but the thought itself does not fall under the concept. But now consider the thought that every object falls under this concept. Does this thought fall under the concept? It does just in case it does not. I have formulated this antinomy elsewhere (Klement 2002: ch. 5). It proves in effect that even the consistent core of Frege's logic, i.e. Frege's logic minus his naive class theory enshrined

4 Besides this antinomy, there are even simpler antinomies that plague this system. Consider, for example, the class of all senses that pick out classes they are not in. Consider, then, any sense that picks out this class. Is it in the class it picks out? 
in the infamous Basic Law V, becomes inconsistent when expanded to include the commitments of the theory of sense and reference. In order to escape inconsistency, Frege would have to abandon not only his commitment to classes as objective entities, but concepts as well.

Abandoning (C2), however, is no more attractive. The commitment to thoughts and other senses as timeless, mind-independent entities existing in the third realm is one of Frege's most celebrated theses. To abandon it would be to simply admit that Frege's philosophy of language is rotten at the core. Let us consider this only as a last resort.

Let us then instead imagine keeping ontological commitment to thoughts, but attempting instead to reduce the number of thoughts posited. This would be in effect to deny (C3); perhaps there are not as many thoughts as there are classes or concepts. Frege himself explicitly argued that there are an infinite number of thoughts (see e.g. Frege 1979: 136n). However, perhaps we can conclude that while there may be a nondenumerably infinite number of classes and concepts, there are only a denumerably infinite number of thoughts.

But exactly how would such a conclusion be justified? In formulating the antinomy, we showed that a distinct thought exists for every class by showing that for each class there is a thought that all objects are in that class, and for each such class, that thought is different. There are two ways to deny this, either (1) deny that there is such a thought for every class, or (2) deny that the resulting thought is distinct for every class. To take the first route would entail denying principle $\Delta 2$. A thought is about a certain class if and only if a constituent of the thought is a sense picking out that class. Principle $\Delta 2$ guarantees that for every class, there is a sense picking it out, and thus, that thoughts exist about every class. We might suggest instead that there are some classes that simply are not picked out by any sense. However, this route is fraught with peril. As I suggested before, this seems to entail rejecting the principle of the identity of indiscernibles. Moreover, in order for this to solve the antinomy, we would have to conclude that $w$ is one such class: that there is no sense picking out $w$. However, this would mean that we would have to insist that the expression used to form the definition of $w$ in our logical language lacked a sense-because, surely, if it had a sense, that sense would pick out $w$. This would entail that not every well-formed expression in our logical language expresses a sense, and even that it is possible for expressions to have a reference but no sense! This would violate some of the core principles of Frege's philosophy of language.

Suppose we take the route second route instead, admitting that one can generate a thought for every class, but denying that the thoughts so generated are distinct for every class. Thus, we would allow that the thought expressed by the proposition ' $(\forall x)(x \in m)$ ' could be the same as that expressed by the proposition ' $(\forall x)(x \in w)$ ', even if ' $m$ ' and ' $w$ ' do not name the same class (i.e. allow $\left(\Pi x^{*}\right)\left(x^{*} \varepsilon m^{*}\right)=\left(\Pi x^{*}\right)\left(x^{*} \varepsilon w^{*}\right)$ without $\left.m^{*}=w^{*}\right)$. I find this suggestion extremely puzzling and difficult to fathom. According to principle $\Delta 4$, thoughts are structured wholes; identical thoughts must be composed of the same senses picking out the same objects. Because the senses of ' $m$ ' and ' $w$ ' are parts of the thoughts expressed by ' $(\forall x)(x \in m)$ ' and ' $(\forall x)(x \in w)$ ', these thoughts could be same only if the senses are the same; and these senses could be the same only if they pick out the same class.

If, however, we deny the principle that thoughts are composed of the senses of the sentences expressing them, there may be room for such an approach. Justification for such an approach might derive from adopting a very different account of the identity 
conditions of thoughts. For example, suppose we assume that sentences express the same thought whenever they are logically equivalent. This view is arguably found in the work of the early Wittgenstein and like-minded thinkers. In that case, then ' $(\forall x)[(x$ $m) \supset(x \in m)]$ ' expresses the same thought as ' $(\forall x)[(x \in w) \supset(x \in w)]$ ', because both are logical truths. Yet, one cannot conclude from this that $m$ is the same class as $w$. Allowing ' $(\forall x)(x \in m)$ ' and ' $(\forall x)(x \in w)$ ' to express the same thought even if $m$ and $w$ are different classes requires looser identity conditions still, but perhaps there could be room for such a view.

The problem, however, is that the looser we make the identity conditions for thoughts, the more likely we are to encounter belief puzzles. Frege's account of statements of belief and other propositional attitudes is that expressions occurring in such contexts refer to their customary senses. This would mean that propositions expressing the same thought should be interchangeable even in oblique contexts. If we adopt loose identity conditions for thoughts, such as logical equivalence, we run into difficulties. The proposition ' $p$ ' is logically equivalent to the proposition ' $\sim(p \&$ $\sim q) \supset \sim(q \supset \sim p)^{\prime}$. Yet these two are clearly not interchangeable in statements of propositional attitudes. A person may believe one and not the other. Moreover, given Frege's logicist belief that all mathematical truths are logically true, adopting such loose identity conditions for thoughts would have for him the absurd result that all true mathematical propositions express the same thought. However, one of Frege's primary motivations for the theory of sense and reference was to explain the difference in cognitive content between the proposition ' $12=12$ ' and the proposition ' $5+7=12$ ' (see e.g. Frege 1979: 224). In order for the sense/reference distinction to do the things it was designed to do, thoughts have to be rather fine-grained. If so, then it will be impossible to take this strategy. If we are willing to admit that for every class there is a thought that everything is in that class, we will have to maintain that this thought is different for every class.

There is a genuine quandary surrounding the belief conditions of thoughts. The number of thoughts posited is inversely proportional to how loose we make their identity conditions; the more thoughts we identify, the fewer we actually posit. However, if we make the identity conditions of thoughts too loose, thoughts are no longer fine-grained enough to do what we want them to do, such as explain the difference in informativity between different mathematical statements or solve the belief puzzles. However, if we make the identity conditions of thoughts too stringent, we commit ourselves to so many that it is very difficult to avoid Cantorian paradoxes. This might be enough to make even those of us who are otherwise attracted to a Fregean account of meaning in terms of intensional entities such as senses to sympathize with Quine's complaint that 'intensions are creatures of darkness', ever bewildering us with their elusive identity conditions (Quine 1956, 188: 193).

There is, however, one remaining possibility for avoiding the antinomy. This would be to deny (C4), the principle that for every class and every thought, the question arises as to whether the thought is in the class. If we divide thoughts into varying logical types, and suggest that classes of thoughts are limited to members of only one logical type, we might insist that the problematic thought $r$, the thought that all objects are in $w$, is not of the correct logical type for the question to even arise as to whether $r$ is in $w$. It was noted earlier that this antinomy is not solved by the simple theory of types. Indeed, something very similar to the simple theory of types is already built into Frege's logic via his distinction between objects, and functions of varying levels. If this is our only type-distinction, we are forced to include all thoughts in the 
type of objects. What is needed is a ramified type theory. Therein, we would divide thoughts into various orders. The underlying principle would be something such as this: if a certain thought represents the sense of a proposition involving a bound variable, the thought itself cannot be included in the range of that variable. In the lowest order, one would have ordinary non-general thoughts, such as those expressed by 'Socrates is bald' or 'Hypatia is wise'. Thoughts that involve either quantification over such thoughts, or that involve classes of such thoughts, would be in the next higher order, and so forth. This would solve the Principles Appendix B paradox in the following manner. If $w$ is a class of thoughts, $w$ is defined only over thoughts of a certain order. Let $n$ be the order of the thoughts in $w$. If we now define $r$ as a thought about $w$ (a thought that includes as constituent a sense picking out $w$ ), then $r$ must be of a higher order than $n$, because $r$ involves a class of entities of order $n$. If this is the case, then the question could not arise as to whether $r$ is in $w$.

Although ramification does solve the antinomy, we need to be careful. We do not want to simply adopt ramification as an ad hoc dodge of the antinomy. We require solid philosophical justification for ramification. However, it is not clear that the standard sorts of justifications for ramification are consistent with Frege's understanding of thoughts. Normally ramification would be justified by an appeal to some sort of 'vicious circle principle'. However, what is vicious about a thought involving a range of entities that may include the thought itself? Consider for example the logical truth that everything is self-identical. I see no reason why the thought itself cannot be one of the things that must be self-identical in order for the thought to be true. One might complain that this thought is about itself, but this is only very indirectly so. This thought is in no way paradoxically contained in itself. The thought is about every entity, but it does not contain every entity within it, nor even a sense picking out every entity. It only contains the sense of the quantifier, which picks out a certain secondlevel function. This function maps its argument function on to the True just in case it has the True for all objects as argument, but this function itself does not contain or otherwise directly presuppose any particular objects.

For Frege, thoughts have an objective, timeless existence in a third realm. If thoughts had a very different sort of existence, matters may be different. For example, if general thoughts were defined or constructed into being in virtue of a pre-existing range, then we might be able to explain what makes the circle vicious. If thoughts were linguistic entities, then we might be able to appeal to a Tarskian hierarchy of languages to justify the division. However, if we are committed to maintaining Frege's own understanding of thoughts as independent of mind and language, these options are not available. Indeed, in the appendix to the second volume of the Grundgesetze in which he discusses the Russell paradox, Frege considered the possibility of dividing objects into different 'types' and restricting concepts (and thus their extensions) to apply only to certain types of objects as arguments. However, he was not very attracted to the idea. His attitude seems to be this: if a so-called 'object' does not fall into the same range as other objects such that the same questions arise as to what concepts it falls under and what classes it is included in, then the so-called 'object' is not a proper object at all (Frege 1964: 128-129). If we are going to regard thoughts and other complete senses as objectively existing objects in the full sense, then we must be willing to place them in the same logical type with more ordinary objects such as chairs, trees and people.

Therefore, it is extremely difficult to deny any of (C1) through (C4) while maintaining all of the core principles of Frege's logic and philosophy of language. Yet, 
if we hold all of (C1) through (C4), we cannot avoid contradiction. The conclusion should be clear: one or more of the core principles in Frege's logic or philosophy of language must be mistaken. For those of us who are sympathetic to the Fregean approach, we need to take a close and critical look at Frege's philosophy of language and the robust ontology of senses that it entails. Whether it is possible to find a way of revising the core principles of Frege's philosophy of language that preserves its spirit and overall form remains to be seen. In any case, the Principles of Mathematics Appendix B paradox must be a concern at some level to any philosophy of language that makes reference to intensional entities, whether they be Fregean thoughts, Russellian propositions or something else. We are therefore left with the choice of either siding with Quine, and eschewing intensions altogether, or plunging one more time into the darkness where these creatures reside in the attempt to ferret out their true nature.

\section{References}

Anderson, C. A. 1977. 'Some models for the logic of sense and denotation with an Application to Alternative (0)', PhD thesis, University College of Los Angeles.

Anderson, C. A. 1986. 'Some difficulties concerning Russellian intensional logic', Noûs 20, 35-43.

Anderson, C. A. 1987. 'Semantic antinomies in the logic of sense and denotation', Notre Dame Journal of Formal Logic 28, 99-114.

Anderson, C. A. 1989. 'Russellian intensional logic', in J. Almog, J. Perry and H. Wettstein, eds. Themes from Kaplan, New York: Oxford University Press.

Church, A. 1951. 'A formulation of the logic of sense and denotation', in P. Henle, H. Kallen and S. Langer, eds. Structure, Method and Meaning: Essays in Honor of H. M. Sheffer, New York: Liberal Arts Press.

Church, A. 1973-4. 'Outline of a revised formulation of the logic of sense and denotation', parts 1-2, Noûs, 7, 24-33, Noûs 8, 135-156.

Church, A. 1984. 'Russell's theory of identity of propositions', Philosophia Naturalis 21, 513-22.

Church, A. 1993. 'A revised formulation of the logic of sense and denotation, Alternative (1)', Noûs 27, $141-57$.

Dummett, M. 1981. Frege: Philosophy of Language, 2nd edn. Cambridge, MA: Harvard University Press. Frege, G. 1964. Basic Laws of Arithmetic: Exposition of the System, ed. and trans. M. Furth, Berkeley: University of California Press (Originally published as Grundgesetze der Arithmetik, 2 vols. Jena: Hermann Pohle, 1893-1903).

Frege, G. 1979. Posthumous Writings, ed. by H. Hermes, F. Kambartel and F. Kaulbach, Chicago: University of Chicago Press [1979]. Originally published as Nachgelassene Schriften (Hamburg: Felix Meiner, 1969).

Frege, G. 1980. Philosophical and Mathematical Correspondence, ed. by G. Gabriel, H. Hermes, H. Kambartel, C. Thiel and A. Veraart, Chicago: University of Chicago Press (Originally published as Wissenschaftlicher Briefwechsel, Hamburg: Felix Meiner, 1976).

Frege, G. 1984. Collected Papers on Mathematics, Logic and Philosophy, ed. by Brian McGuinness, Chicago: University of Chicago Press (Originally published as Kleine Schriften, Hildesheim: Georg Olms, 1967).

Geach, P. T. 1976. Review of Frege: Philosophy of Language, by M. Dummett, Mind 85, 436-49.

Kaplan, D. 1964. 'Foundations of intensional logic', PhD thesis, University College of Los Angles.

Kaplan, D. 1969. 'Quantifying in', in A. P. Martinich, ed. The Philosophy of Language, 3rd edn, New York: Oxford University Press.

Klement, K. 2002. Frege and the Logic of Sense and Reference, New York: Routledge.

Landini, G. 1998. Russell's Hidden Substitutional Theory, New York: Oxford University Press.

Myhill, J. 1958. 'Problems arising the formulation of intensional logic', Logique et Analyse 1, 78-83.

Quine, W. V. 1956. 'Quantifiers and propositional attitudes', in W. V. Quine, ed. The Ways of Paradox and Other Essays, Cambridge, MA: Harvard University Press.

Russell, B. 1903. Principles of Mathematics, 2nd. edn, New York: W. W. Norton.

Russell, B. 1980. Correspondence with Frege, in G. Frege, Philosophical and Mathematical Correspondence, Chicago: University of Chicago Press, pp. 130-70. 
Copyright of History \& Philosophy of Logic is the property of Taylor \& Francis Ltd and its content may not be copied or emailed to multiple sites or posted to a listserv without the copyright holder's express written permission. However, users may print, download, or email articles for individual use. 